Адрес статьи / To link this article: http://cat.ifmo.ru/ru/2017/v2-i4/123

\title{
Международный семинар «Информационные технологии и культура»
}

\author{
Е.Е. Елькина ${ }^{2}$, Д.Е. Прокудин ${ }^{1,2}$ \\ ${ }^{1}$ Санкт-Петербургский государственный университет, Россия \\ ${ }^{2}$ Университет ИТМО, Россия \\ e.e.e.1@mail.ru, hogben.young@gmail.com
}

\begin{abstract}
Аннотация. В 2017 году с рамках проведения XX международной объединённой научной конференции «Интернет и современное общество» был организован международный семинар «Информационные технологии и культура» («Information Technology and Culture» — ITC-2017), который состоялся 21-22 июня. Данный обзор описывает проведение и результаты семинара.
\end{abstract}

Ключевые слова: культура, технологии, информационное общество, Интернет и современное общество, международный семинар

Проводимая с 1998 года в Санкт-Петербурге международная объединённая научная конференция «Интернет и современное общество» (Internet and Modern Society — IMS), в 2017 году отпраздновала свой юбилей - 20-летие. С 21 по 23 июня была проведена юбилейная XX конференция. С 2016 года она объединяет серию различных научных мероприятий и проходит в формате Недели технологий информационного общества в Санкт-Петербурге, организуемой Университетом ИТМО (http://ifmo.ru).

Одна из основных целей проведения конференции «Интернет и современное общество»способствовать формированию в России сообщества специалистов, ведущих исследования и разработки в области технологий информационного общества. Конференция способствуют изучению зарубежного опыта и развитию международного сотрудничества в данной области.

Динамика развития информационного общества порождает появление и развитие информационно-коммуникационных технологий, которые находят своё применение в различных областях человеческой деятельности, что постоянно актуализирует интерес исследователей в различных и, прежде всего, междисциплинарных областях. Организаторы конференции «Интернет и современное общество» отслеживают эти тенденции и постоянно модернизируют научную программу с тем, чтобы её участники обсуждали наиболее актуальные направления развития технологий информационного общества. Так, в 2017 году в рамках объединённой научной программы конференции был организован международный научный симпозиум «Интернет и современное общество» (International Symposium «Internet and Modern Society» - IS IMS-2017) [2]. Симпозиум состоял из нескольких научных семинаров. Один из них, международный семинар «Информационные технологии и культура» («Information Technology and Culture» - ITC-2017), состоялся 21-22 июня 2017 г. Он был посвящён обсуждению актуальных вопросов и тенденций взаимодействия культуры и технологий. Участниками семинара были рассмотрены как вопросы 
развития технологических решений в области культуры, так и социогуманитарные аспекты и проблемы влияния информационных технологий на трансформацию культуры. Рабочим языком семинара был английский. Для участия в семинаре были поданы 42 заявки. Международный программный комитет семинара (представители 27 стран) в результате процедуры двойного слепого рецензирования отобрал для участия в семинаре 20 статей. Из них 9 докладов были заслушаны, а 11 были представлены в рамках объединённой постерной сессии конференций «Интернет и современное общество» (IMS-2017) и Digital Transformation \& Global Society (DTGS-2017).

Работа семинара включала две панельные дискуссии:

- Information Technology \& Culture Transformation (Информационные технологии и трансформация культуры);

- Science and Higher Education in the Information Networks (Наука и высшее образование в информационных сетях).

С ключевыми докладами выступили представитель Университета ИТМО, декан факультета технологического менеджмента и инноваций, доцент Филипп Казин, Unpredictable Technological Future and Ideals of Russian Culture (Непредсказуемое будущее технологического развития и идеалы русской культуры) и профессор Нагпурского университета, доктор Нилам Тиккха, Interaction of Technology and Culture: Empirical Study (Взаимодействие технологии и культуры: эмпирическое исследование).

Доклад Ф. Казина был посвящен анализу этических проблем, вытекающих из современной цифровой технологической революции, которая создает непредсказуемое будущее для развития общества и человека в виду интеграции человеческого интеллекта и роботизированных систем управления. Глобальные экономические и политические процессы приводят к неопределенности в отношении будущего управления технологическим развитием, которое все чаще находится в руках отдельных лиц или элитных групп, или даже в руках преступников. Для преодоления негативных тенденций технологизации общества и преодоления глобальных угроз докладчик призывает к широкому использованию в социальной практике традиций русской культуры с опорой на христианские ценности равенства, социальной справедливости и взаимной помощи для достижения техногуманитарного баланса. Подобная стратегия, считает Казин, будет способствовать достижению Россией положения мировых лидеров в перспективе 2035 г.

Доклад Н. Тиккха представляет исследование влияния информационных технологий на индийскую культуру. Индия характеризуется многообразием форм традиционной культуры и религиозных верований. Несмотря на приверженность Индии традициям в общественном развитии, информационные технологии играют важную роль в современном индийском обществе: в сфере образования и науки, в сохранении культурного наследия, в развитии коммуникаций, в т.ч. с использованием Интернета для отправления религиозных ритуалов, осуществления покупок и т.п. Согласно результатам опроса, проведенного докладчиком, традиционная культура и новации с использованием информационных технологий взаимодополняют друг друга в современной Индии.

В панельной дискуссии «Информационные технологии и трансформация культуры» было представлено три доклада:

1. Out-Convergence: Co-evolution of Media and Reality of Life (Ко-эволюция средств массовой информации и реальности жизни как следствие конвергенции), В. Голубев, О. Филатова, А. Ульяновский, Т. Доброва, А. Смирнов, Санкт-Петербургский государственный университет. В докладе обсуждались новые тенденции в развитии СМИ на основе конвергентных технологий и их влияние на ко-эволюцию смежных областей культуры, социальные практики и восприятие реальности.

2. CHPC-Complex Prototype: a Model-Based Software and Hardware Approach to Indoor Microclimate Management for Cultural Heritage Preservation and Conservation (Прототип КСКНкомплекса: подход на основе модели программного и аппаратного обеспечения к управлению микроклиматом для сохранения и защиты культурного наследия), Р.Хайдарова, М. Лапаев, И. Бондаренко, Университет ИТМО. Авторы представили анализ подходов с использованием 
программного и технического обеспечения к управлению микроклиматом выставочных пространств с учетом их преимуществ и недостатков.

3. Quantified Construction of Self: Numbers, Narratives and the Modern Individual (Оцифровка личности: числа, нарратив и современный индивид), Ю. Степанчук, Уральский федеральный университет, Екатеринбург. Автор исследует общие философские, социальные и культурные аспекты перехода от культуры, основанной на технологиях печатного текста, к цифровой культуре и влияние цифровых трансформаций на формирование, идентификацию и самопознание личности.

Панельная дискуссия «Наука и высшее образование в информационных сетях» включала четыре доклада:

1. The Problem of Contemporary Science Representation in Informational Networks (Проблема представления современных научных исследований в информационных сетях), Е. Чеботарева, Л. Шиповалова, Санкт-Петербургский государственный университет. Авторами были рассмотрены такие проблемы представления современной науки в информационных сетях, как способы управления научными исследованиями, в т.ч., наукометрические измерения как инструмент управления развитием научных исследований; проблема научных коммуникаций; импакт-факторы и индексы цитирования: их положительные и отрицательные стороны и др. Авторы утверждают, что с эпистемологической точки зрения представление науки в сети изменяют критерии научности, стили научной работы, роль коммуникаций в научных исследованиях.

2. Modern Information Technologies as a Tool for Research and Presentation of Narrative: Possible Ways of Application in Historical Science (Современные информационные технологии как средство исследования и представления текста: возможные способы их применения в исторической науке), О. Кузьмина, А. Милославов, Университет ИТМО. В докладе был представлен анализ проблемы адекватного применения ИКТ в научной и образовательной практике исторической науки. Основываясь на концепции косвенного общения и взаимопонимания Мусхелишвили-Шредера, авторы предлагают создать открытый ресурс, позволяющий использовать комментарии читателей в исторических исследованиях.

3. Formation of the Information Culture and Media Literacy in Modern University Communities: a Comparative Analysis of the Experience of Russian and American Universities (Формирование информационной культуры и медиаграмотности в современном университетском сообществе: сравнительный анализ опыта российских и американских университетов), Е. Елькина, Университет ИТМО. Автором представлен анализ основных подходов к определению понятия информационной культуры, ее структуры и принципов в отечественной и американской литературе; определены общие и специфические тенденции ее формирования в университетах России и США. Автор отмечает, что различные уровни развития информационной культуры в российских и американских университетах объясняются особенностями моделей национального высшего образования в России и США, степенью интеграции университетов в мировую электронную образовательную среду и уровнем финансирования образования.

4. From the E-Learning and Blended-Learning to M-Learning: Trends, Benefits and Risks of Education Digital Transformation (Трансформация образования как движение от е-обучения к смешанным формам обучения и м-обучению: преимущества и риски цифровой трансформации системы образования), О. Гучинская, Л. Краева, Университет ИТМО. Согласно авторам, компетентностный подход к реализации образовательных программ требует более адекватного выбора образовательных методик и технологий для достижения лучших результатов в обучении. В докладе представлен анализ развития современных образовательных технологий, рассмотрены причины перехода от е-обучения как более перспективной альтернативы традиционным формам обучения к смешанным формам обучения и к модели мобильных университетов с учетом связанных с ними рисков. 
В постерной сессии было представлено 10 исследований. Их большая часть посвящена:

а) проблемам роли Интернета в современных научных исследованиях:

- Issues of Public Multimedia Analysis in Socio-Cultural Researches (Проблемы анализа мультимедиа в социокультурных исследованиях), А. Бершадский, А. Тимонин, А. Бождай, О. Кошевой, Пензенский государственный университет;

- Selection Methods of Digital Information Resources for Scientific Heritage Studies: A Case Study of Georgy F. Gause (Методы выбора цифровых информационных ресурсов для исследований научного наследия: тематическое исследование Георгия Ф. Гаузе), Д. Прокудин, Г. Левит, Университет ИТМО и Уве Хосфельд, Университет Йены, Германия);

- Internet Video Resources as a Tool for Analyzing Dissemination of Russian Musical Culture (Интернет видео ресурсов как инструмент для анализа распространения русской музыкальной культуры), Т. Шерстинова и Г. Мартыненко, Санкт Петербургский государственный университет;

б) анализу положительных и отрицательных факторов использования информационных технологий и Интернета в сфере образования:

- Enhancement of IT-Professional Education: Russian-Kazakh Network of the IT-Training Centers (Повышение профессионального образования в сфере информационных технологий: сеть российско-казахских центров IT-обучения), Д. Черчимцева, О. Долинина, А. Бровко, Саратовский государственный технический университет им. Юрия Гагарина и Л. Бобров, Новосибирский государственный университет;

- Culture of Social Media Interactions Amongst Modern Students: Analysis of the Social Network vk.com, University Groups "Overheard..." with Big Data (Культура взаимодействия социальных средств массовой информации среди современных студентов: анализ социальных сетей “В контакте.сот", университетских групп "На высоте” с большой базой данных), А. Мальцева, Санкт Петербургский государственный университет, А. Клебанов, Н. Шилкина, О. Махниткина, Алтайский государственный университет и И. Лямкин, Л.С. Бинсэд, Университет ИТМО;

- Assessment of Internet Addiction Level of Pupils and its Prevention on School Information and Educational Environment (Оценка уровня Интернет-зависимости учащихся и ее профилактика в школьной информационно-образовательной среде), А. Федосов, Российский государственный социальный университет, Москва;

в) исследованию роли информационных технологий в сохранении культурного наследия:

- Digital Libraries in Russian Segment of Internet: the Analysis of Open Access to Cultural Heritage Objects («Электронные библиотеки в российском сегменте Интернета: анализ открытого доступа к объектам культурного наследия»), Н. Тарумова, исследовательский вычислительный центр Московского государственного университета им. Ломоносова;

г) проблемам информационной безопасности:

- Logosphere: Information Security in the Context of Social Health (Логосфера: Информационная безопасность в контексте социального здравоохранения), Т. Федорова, Т. Петрушенко и Н. Клинецкая, Санкт-Петербургский государственный университет);

д) анализу новых тенденций в развитии информационного общества (принципы формирования социальных сетей; влияние медийных технологий СМИ на общественное сознание и социальные практики; человеческий капитал и его роль в современном обществе, и др.):

- Synchronization of News, Opinions and Experiences of the Culture Sphere in Various Social and Language Groups Using the Digital Infrastructure "Common World" (Синхронизация новостей, мнений и практик в сфере культуры в различных социальных и языковых группах, использующих цифровую инфраструктуру “Общий мир”), А. Третьяков, М. Иващенко и В. Стромцова, Университет ИТМО;

International Culture \& Technology Studies, Vol. 2, No. 4 
- The Identification of Communities in the Cyberspace of Social Networks Based on Average Measure of Similarity (Выявление сообществ в киберпространстве социальных сетей на основе средних показателей сходства), Н. Горлушкина, С. Иванов, М. Хлопотов, Университет ИТМО;

- Human Capital in the Information Society and the Wage Difference Factors (Человеческий капитал в информационном обществе и факторы, определяющие разницу в оплате труда), А. Алетдинова, М. Бакаев, Новосибирский государственный технический университет.

В завершение работы семинара выступил директор международного симпозиума «Интернет и современное общество» Д.Е. Прокудин, который представил участникам семинара новый международный научный электронный журнал «Культура и технологии» (Multimedia Online Journal «International Culture \& Technology Studies») [1], задачей которого является создание междисциплинарной площадки для обсуждения актуальных вопросов и тенденций взаимодействия культуры и технологий. Целевой аудиторией издания являются сотрудники организаций культуры, университетов и научных лабораторий, творческие работники, специалисты в области информационно-коммуникационных технологий и креативных индустрий, исследователи социально-гуманитарных и технологических аспектов развития культуры и искусства.

Научные статьи, публикуемые в журнале, описывают опыт использования современных технологий при реализации проектов сохранения культурного наследия и обеспечения широкого доступа к культурным ценностям, творческих проектов в области современного искусства, а также результаты научных и технологических разработок, направленных на создание новых технологий в сфере культуры.

Журнал «Культура и технологии» призван распространять актуальные результаты проектов, теоретических и прикладных исследований и разработок, проводимых как в России, так и за рубежом, нацеленных на эффективное взаимодействие культуры, искусства и технологий.

Материалы журнала представляют интерес для представителей бизнес структур, занимающихся разработкой и внедрением инновационных технологий, в том числе, программных и аппаратных систем в области компьютерной графики и виртуальной реальности, а также информационно-коммуникационных технологий и интернет решений для учреждений культуры, науки и образования.

Журнал «Культура и технологии» нацелен также на привлечение внимания представителей органов государственной власти и организаций сектора туризма к потенциалу современных технологий в области культуры и искусства.

Отличительной особенностью издания является наличие на его страницах статей с мультимедийным активным материалом: полноцветные высоко качественные изображения, галереи изображений («слайдеры»), видео, видео 360, объёмное (панорамное) изображение, 3D-туры и инсталляции с интерактивным управлением и пр. Сайт журнала реализован в концепции электронной издательской системы полного цикла - от подачи материалов в журнал до выхода в свет очередного номера. Все мультимедийные материалы размещаются на выделенном сервере, что обеспечивает гарантированное долговременное хранение содержания журнала.

По итогам работы международного симпозиума «Интернет и современное общество» был подготовлен и издан сборник трудов на английском языке [3], в который вошли статьи участников международного семинара «Культура и технологии». До конца 2017 года статьи сборника были проиндексированы в международной реферативной научной базе SCOPUS.

В целом, организация и проведение международного симпозиума «Интернет и современное общество» показало возможность и целесообразность знакомства международной научной общественности с российскими исследованиями технологий информационного общества, а участие в симпозиуме зарубежных коллег обогатило отечественное научное сообщество зарубежным исследовательским опытом. 


\title{
Литература
}

[1] Культура и технологии. http://cat.ifmo.ru.

[2] International Conference "Internet and Modern Society" (IMS-2017). http://icims.ifmo.ru.

[3] Internet and Modern Society: Proceedings of the International Conference IMS-2017 (St. Petersburg; Russian Federation, 21-24 June 2017). Eds Radomir V. Bolgov, Nikolai V. Borisov, Leonid V. Smorgunov, Irina I. Tolstikova, Victor P. Zakharov. ACM International Conference Proceeding Series. N.Y.: ACM Press, 2017. ix, 291 p. ACM ISBN: 978-1-4503-5437-0. https://dl.acm.org/citation.cfm?id=3143699.

\section{International Workshop "Information Technology and Culture"}

\author{
E. Elkina ${ }^{1}$, D. Prokudin ${ }^{1,2}$ \\ ${ }^{1}$ ITMO University, Russia \\ ${ }^{2}$ Saint-Petersburg State University, Russia
}

\begin{abstract}
The International Workshop "Information Technology and Culture" (ITC-2017) was held in June 21-22, 2017 in connection with the celebration of the twentieth International Joint Conference "Internet and Modern Society" (IMC-2017). The review describes the discussion on the workshop and its results.
\end{abstract}

Keywords: culture, technology, information society, Internet and modern society, international workshop.

\section{References}

[1] International Culture \& Technology Studies. http://cat.ifmo.ru.

[2] International Conference "Internet and Modern Society" (IMS-2017). http://icims.ifmo.ru.

[3] Internet and Modern Society: Proceedings of the International Conference IMS-2017 (St. Petersburg; Russian Federation, 21-24 June 2017). Eds Radomir V. Bolgov, Nikolai V. Borisov, Leonid V. Smorgunov, Irina I. Tolstikova, Victor P. Zakharov. ACM International Conference Proceeding Series. N.Y.: ACM Press, 2017. ix, 291 p. ACM ISBN: 978-1-4503-5437-0. https://dl.acm.org/citation.cfm?id=3143699. 